4-1-2008

\title{
Fluorescent Si Nanoparticle-Based Electrode for Sensing Biomedical Substances
}

\author{
Gang Wang \\ Cleveland State University
}

Siu-Tung Yau

Cleveland State University, s.yau@csuohio.edu

Follow this and additional'works at: https://engagedscholarship.csuohio.edu/enece_facpub

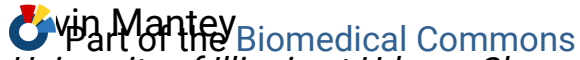
University of Illinois at Urbana-Champaign

How does access to this work benefit you? Let us know!

\section{Punblishitealseßstatement}

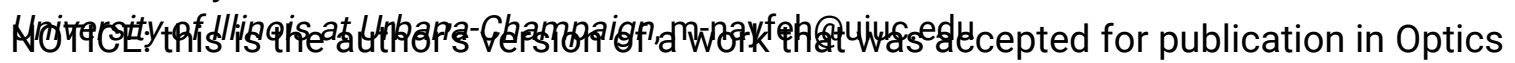

Communications. Changes resulting from the publishing process, such as peer review, editing, corrections, structural formatting, and other quality control mechanisms may not be reflected in this document. Changes may have been made to this work since it was submitted for publication. A definitive version was subsequently published in Optics Communications, 281, 7, (04-01-2008); 10.1016/j.optcom.2007.07.070

\section{Original Citation}

Wang, G., Yau, S., Mantey, K., , \& Nayfeh, M. H. (2008). Fluorescent Si nanoparticle-based electrode for sensing biomedical substances. Optics Communications, 281(7), 1765-1770. doi:10.1016/ j.optcom.2007.07.070

\section{Repository Citation}

Wang, Gang; Yau, Siu-Tung; Mantey, Kevin; and Nayfeh, Munir H., "Fluorescent Si Nanoparticle-Based Electrode for Sensing Biomedical Substances" (2008). Electrical Engineering \& Computer Science Faculty Publications. 62. https://engagedscholarship.csuohio.edu/enece_facpub/62

This Article is brought to you for free and open access by the Electrical Engineering \& Computer Science Department at EngagedScholarship@CSU. It has been accepted for inclusion in Electrical Engineering \& Computer Science Faculty Publications by an authorized administrator of EngagedScholarship@CSU. For more information, please contact library.es@csuohio.edu. 


\title{
Fluorescent Si nanoparticle-based electrode for sensing biomedical substances
}

\author{
Gang Wang ${ }^{a}$, Siu-Tung Yau ${ }^{a}$, Kevin Mantey ${ }^{b}$, Munir H. Nayfeh ${ }^{\text {b,* }}$ \\ ${ }^{a}$ Department of Electrical and Computer Engineering, Cleveland State University, Cleveland, OH 44115, USA \\ ${ }^{\mathrm{b}}$ Department of Physics, University of Illinois at Urbana-Champaign, 1110W. Green Street, Urbana, IL 61801, USA
}

Direct electrochemical detection has been explored for three decades for making stable and miniature sensors for biomedical applications. This sensing approach is adopted to replace enzyme-based sensors due to enzymes' intrinsic instability under physiological conditions. To date, enzyme-free sensors have been made using noble metals [1,2], alloys of these metals [3], conducting polymers [4] and carbon nanotubes [5]. These sensors, while rendering device stability, still suffer from issues related to material selectivity and/or electrode poisoning due to adsorption of reaction intermediates. Presently, the enzyme, glucose oxidase (GOx), is used as the sensing element for glucose sensors. In this paper we present a high sensitivity sensor electrode using a thin film of silicon nanoparticles as the active material. Not only, nano silicon is one of the least toxic material, but due to its highly efficient luminescence properties, it will enable dual amperometric/optical sensing [6].
We prepare the silicon nanoparticles by pulverizing crystalline silicon wafers using an electrochemical treatment. The process involves gradual immersion of the wafer into a bath of $\mathrm{HF}$ and $\mathrm{H}_{2} \mathrm{O}_{2}$ while arranging for an electrical current to skim the top skin of the wafer [7-10]. $\mathrm{H}_{2} \mathrm{O}_{2}$ catalizes the etching producing ultrasmall structures and cleans impurities and produces a higher electronic and chemical quality with an ideal hydrogen termination. The wafer is then immersed in an ultrasound bath, causing the fragile nanostructure network to dislodge into particles. The procedure produces a family of discrete size $\mathrm{Si}_{n} \mathrm{H}_{x}$ particles that are $1.0\left(\mathrm{Si}_{29} \mathrm{H}_{24}\right), 1.67\left(\mathrm{Si}_{123}\right), 2.15,2.9$, and $3.7 \mathrm{~nm}$ in diameter which can be consequently separated [11]. This is unlike uncapped clusters $\mathrm{Si}_{n}$, whose abundance has been known to exhibit no discrete magic numbers for $n>20$. The smallest four of the particles are ultrabright blue, green, yellow, and red luminescent particles respectively. A thin graphite grid is immersed in the colloid of the $1 \mathrm{~nm}$ particles and imaged by high-resolution TEM as shown in Fig. 1. Electron photospectroscopy shown in Fig. 2 shows that the particles are composed of silicon with less than $10 \%$ oxygen. 


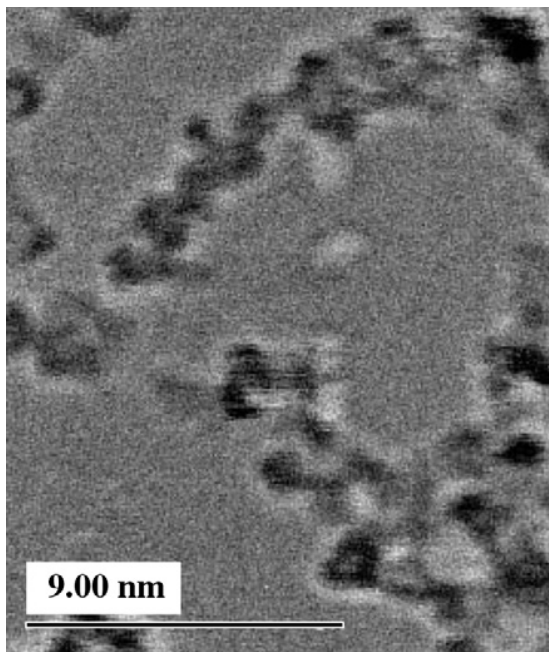

Fig. 1. Transmission electron microscopy image of the Si nanoparticles coating a thin graphite grid.

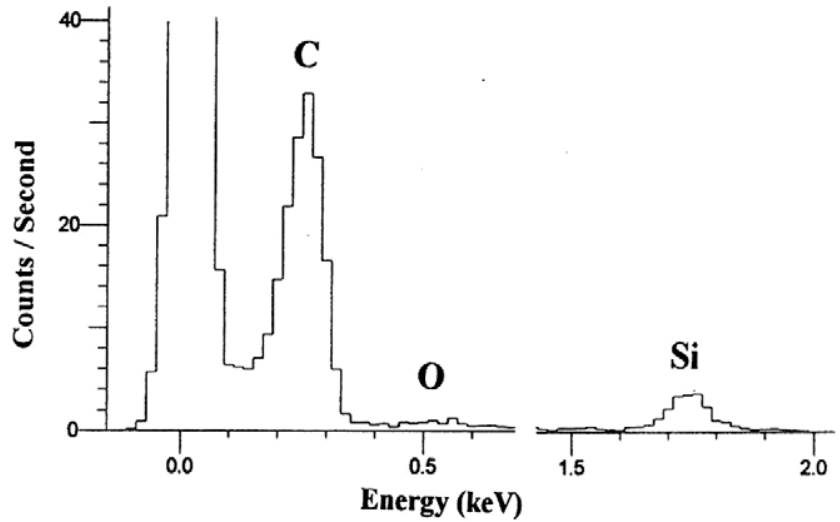

Fig. 2. Material analysis profile of the coated grid using electron photo spectroscopy.

Monte Carlo simulation of the particle suggests a filled fullerene structure of $\mathrm{Si}_{29} \mathrm{H}_{24}$, in which a central core silicon atom and four other silicon atoms are arranged in a tetrahedral coordination and the 24 remaining silicon atoms undergo a $\mathrm{H}$-terminated bulk-like $(2 \times 1)$ reconstruction of dimer pairs on $(001)$ facets $(6$ reconstructed surface dimers) [8]. Fig. 3a shows a schematic model of the $\mathrm{Si}_{29} \mathrm{H}_{24}$ structure.

We prepare a colloid of the $1 \mathrm{~nm}$ particles in benzene. We incubated particles in benzene at room temperature. After incubation in benzene, FTIR and XPS and optical spectroscopy show the formation of permanent $\mathrm{Si}-\mathrm{C}$ bonds, and optical spectroscopy shows more than 30 -fold enhancement in the photoluminescence. Theses new features are a result of the formation of a highly stressed benzene- $\mathrm{Si}_{29}$ nanoparticle butterfly complex on $\mathrm{Si}$ dimers (Fig. 3b). We used Gamess software to determine the equilibrium geometry of the $\mathrm{Si}_{29} \mathrm{H}_{24}$-benzene complex using the RHF theory with $6-311 \mathrm{G}(\mathrm{d}, \mathrm{p})$ basis set. Fig. $3 \mathrm{~b}$ shows the arrangement of a benzene ring when it is attaches to the $\langle 100\rangle$ silicon surface by anchoring via novel
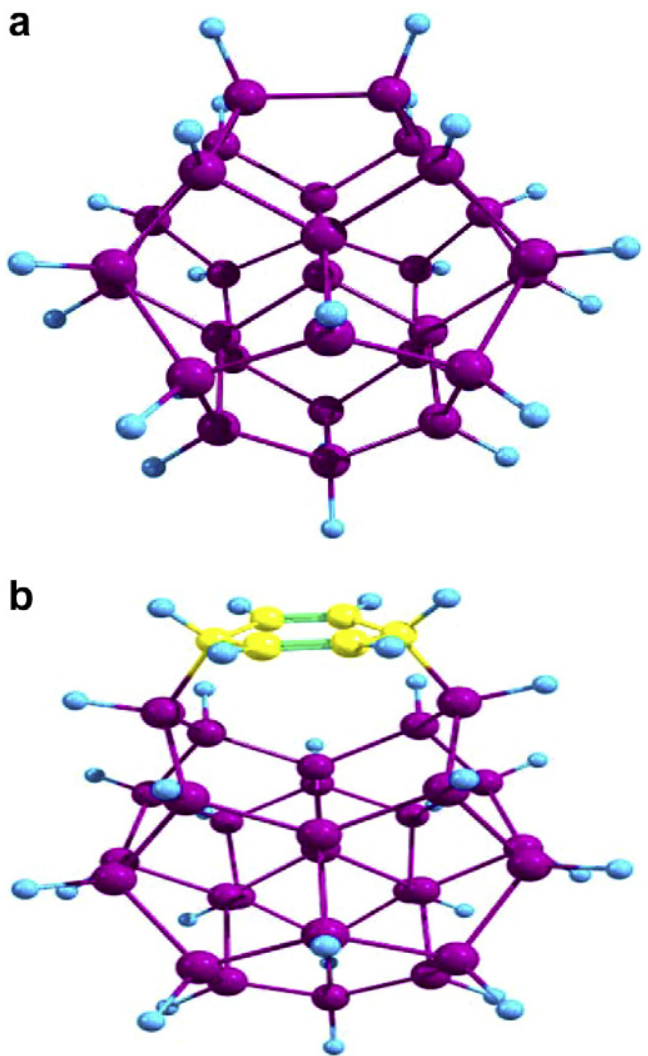

Fig. 3. (a) Schematic structure of the $\mathrm{Si}_{29}$ particle, (b) schematic illustration of a benzene molecule attached to the $\mathrm{Si}_{29}$ particle.

$\mathrm{Si}-\mathrm{C}$ bonds on a reconstructed dimer site in the form of a highly strained complex. The binding to benzene tends to minimize aggregation or agglomeration of the particles on the silicon wafer.

Heavily doped ( $\rho<0.005 \Omega \mathrm{cm}$ ) n-type silicon wafers is used to support $\mathrm{Si}_{29}$ particles as sensing elements for electrochemical detection. The wafer with its surface containing the native oxide is cleaned with ethanol, isopropanol and de-ionized water. The wafer surface is then covered with a mask to achieve a working area of $1 \mathrm{~mm} \times 1 \mathrm{~mm}$. A drop of $0.1 \mathrm{ml}$ of the $\mathrm{Si}_{29}$ colloid is spread on the wafer surface, and the sample is incubated for $10 \mathrm{~h}$ and then rinsed with de-ionized water. The particle-covered wafer is used as the working electrode in a typical three-electrode electrochemical cell for cyclic voltammetry measurements. $\mathrm{An} \mathrm{Ag} / \mathrm{AgCl}$ electrode is used as the reference electrode. The electrochemical cell will be controlled by a high-sensitivity potentiostat with current sensitivity on the femtoampere level. The lowest current scale of this potentiostat is $10 \mathrm{pA}$ full scale with a resolution of $20 \mathrm{fA}$. The potentiostat can be used to perform both cyclic voltammetry and pulse voltammetry. The cell is put inside a Faraday cage, which provides shielding for low-current measurements. Voltammograms is generated at different scan rate of the potential. Substances to be detected using the $\mathrm{Si}_{29}-\mathrm{Si}$ electrode will be dissolved in a phosphate buffer solution (PBS) and introduced into the cell for measurements. Note that 
the bare silicon wafer showed no electrochemical response to the substances used in this work up to a potential as high as $1.6 \mathrm{~V}$.

Fig. 4a is an atomic force microscopy (AFM) image of a typical $\mathrm{Si}_{29}-\mathrm{Si}$ electrode in which silicon nanoparticles are deposited on a silicon wafer. This is an all silicon electrode, consiting of a silicon substrate and a silicon nanoparticle surface film deposited on it. The image shows that the silicon surface is only partly covered with particles. The
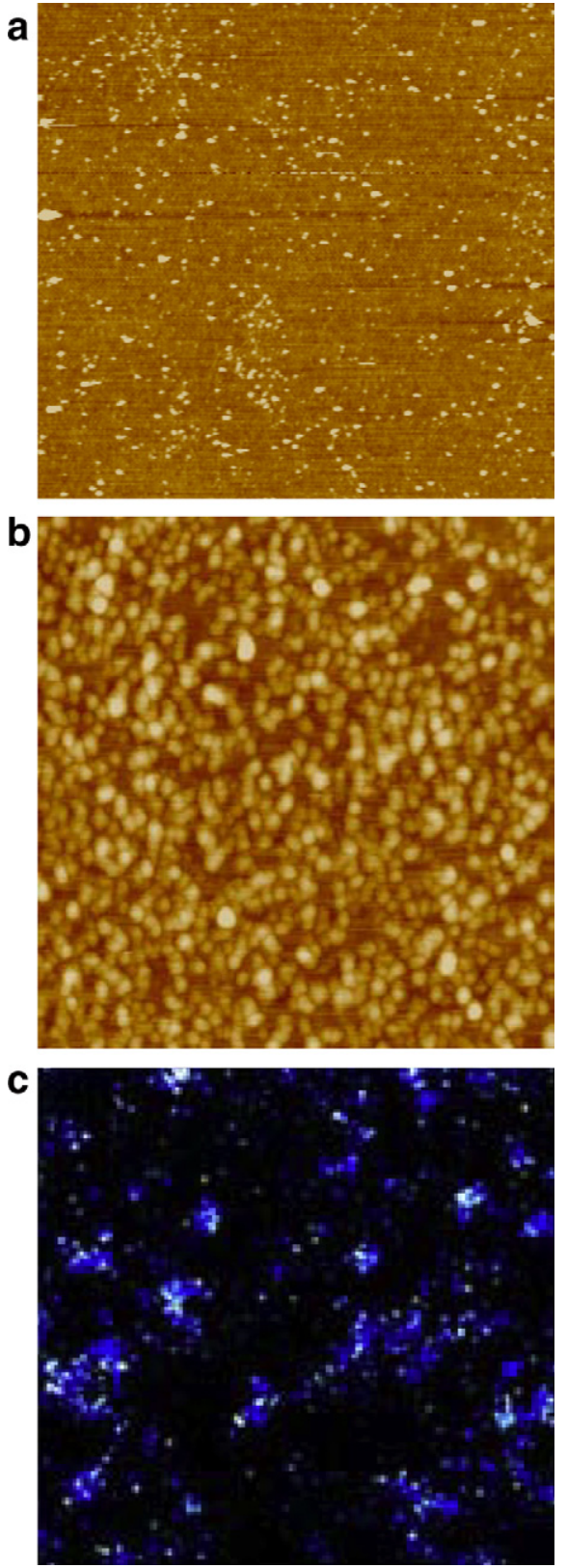

Fig. 4. (a) AFM image $(2 \mu \mathrm{m} \times \mu \mathrm{m})$ of $\mathrm{Si}_{29}$ particles deposited on a silicon electrode to produce an all silicon $\mathrm{Si}_{29}-\mathrm{Si}$ electrode, (b) AFM image $(2 \mu \mathrm{m} \times \mu \mathrm{m})$ of glucose enzyme deposited on a silicon electrode to produce a GOx-Si eelctrode, (c) $3 \times 3 \mu \mathrm{m}$ blue photoluminescence image of $1 \mathrm{~nm}$ particles on a substrate under two-photon excitation in the infrared. (For interpretation of the references to colour in this figure legend, the reader is referred to the web version of this article.) image also shows minimal agglomeration due to binding to benzene rings. It shows isolated spots. The size of each spot is nearly $9 \mathrm{~nm}$. In the lateral direction, resolution of AFM in the sub $10 \mathrm{~nm}$ regime is dominated by the tip effect. It is known that AFM is only accurate in the vertical direction in the sub $10 \mathrm{~nm}$ regime. Performing line profiles through the particles, however, gives a height difference between the maximum and the background edge of $1 \mathrm{~nm}$. This is in agreement with previous TEM imaging of the nanoparticle. Estimation based on Fig. 4a shows that typically there are only $1000 \mathrm{Si}_{29}$ particles within this area. When this electrode is exposed to UV light, blue luminescence is emitted. Also when it is exposed to femto or pico second infrared radiation, the blue luminescence is observed due to a two photon absorption process in the range $680-800 \mathrm{~nm}$ as shown in Fig. 4c.

Fig. 5 shows the $\mathrm{Si}_{29}-\mathrm{Si}$ electrode's response to glucose at $\mathrm{pH}$ 7. The curves are the cyclic voltammograms (CVs) of the electrode. The increase of the anodic current due to the presence of glucose (curve b) above the background (curve a) is clearly shown. The calibration curve of the electrode at $\mathrm{pH} 7$ as shown in the inset is linear over a range of $0-50 \mathrm{mM}$ of glucose, which covers the physiological level of $3-8 \mathrm{mM}$ [12]. The absence of electrode poisoning is reflected in the electrode's reversible response to varying the glucose concentration as indicated by the arrows. Curve $b$ in Fig. 5 indicates that glucose is oxidized at the electrode. As mentioned above, the bare silicon wafer shows no response to glucose. Thus, the $\mathrm{Si}_{29}$ particle shows a catalytic character in the detection of glucose. A study on the effect of sweeping speed of the potential indicates that the current of curve $b$ in excess of curve a is mainly due to glucose and charging current is negligible.

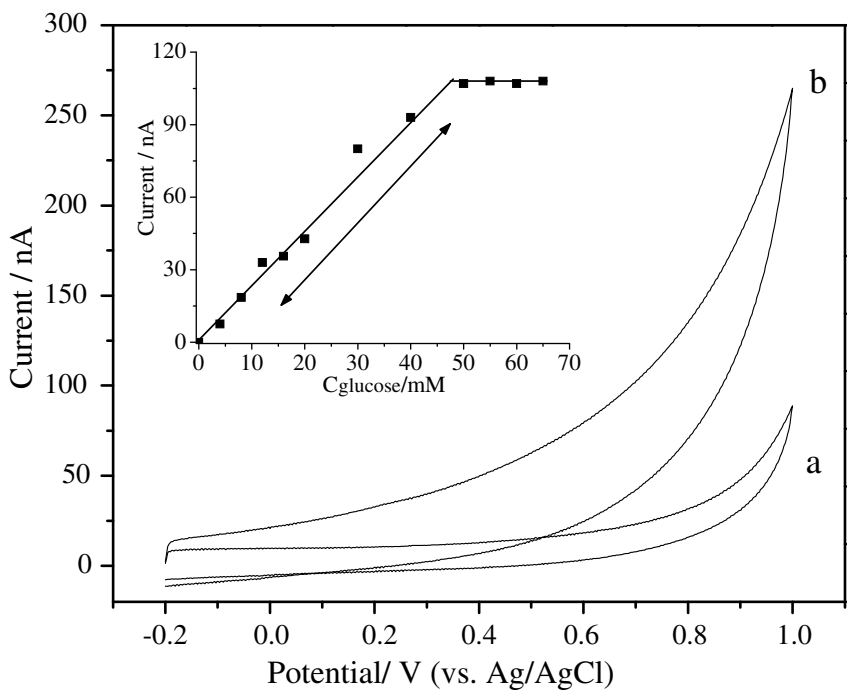

Fig. 5. Current-voltage response of an all silicon $\mathrm{Si}_{29}-\mathrm{Si}$ electrode in $5 \mathrm{mM}$ in PBS (curve a) and in the presence of $30 \mathrm{mM}$ glucose in the PBS curve $b$. The inset shows the electrode's calibration curve obtained at $0.7 \mathrm{~V}$. The arrows indicate the reversibility of the response to the glucose concentrations. 
The time domain response of this all silicon electrode glucose is shown in Fig. 6. It also shows that the presence of three interference agents, ascorbic acid (AA), uric acid (UA) and 4-acetamidophenol (AP), at the physiological levels does not leave any measurable trace on the electrode's response. The electrode's response to glucose under identical conditions over a period of 14 weeks was examined. During this period the electrode was repeatedly used every other day and 10 times per day on the average and was stored under ambient conditions. The measurements showed that the electrode's response has reduced by only $10 \%$ of its initial value on the average.

We prepared another electrode by immobilizing GOx as the active films on the same kind of silicon wafer we used above [13].This provide us with an enzyme-based electrode (GOx-Si). We now compare the glucose response of the all silicon $\mathrm{Si}_{29}-\mathrm{Si}$ electrode to that of the $\mathrm{GOx}-\mathrm{Si}$ electrode. Fig. 4a was an atomic force microscopy (AFM) image of the $\mathrm{Si}_{29}-\mathrm{Si}$ electrode, showing a typical particle distribution on the silicon surface, which is only partly covered with the particles. Fig. $4 \mathrm{~b}$ is an AFM image showing the GOx-Si electrode, where the entire electrode surface is covered with a monolayer of the enzyme. Estimation based on Fig. 4a and $b$ shows that typically there are 4000 GOx molecules or $8000 \mathrm{FAD}$ centers within an electrode surface area of $1 \mu \mathrm{m} \times 1 \mu \mathrm{m}$, while there are only $1000 \mathrm{Si}_{29}$ particles within the same area. Fig. 7 shows the amperometric responses of both kinds of electrode having the same size as the glucose concentration is varied. The response of the $\mathrm{Si}_{29}-\mathrm{Si}$ electrode is at least 4-fold larger than that of the $\mathrm{GOx}-\mathrm{Si}$ electrode.

Characteristic rate constants for the conversion of glucose to glucose-lactone have been calculated using the above results $[6,14-18]$. The results suggest that the $\mathrm{Si}_{29}$ par-

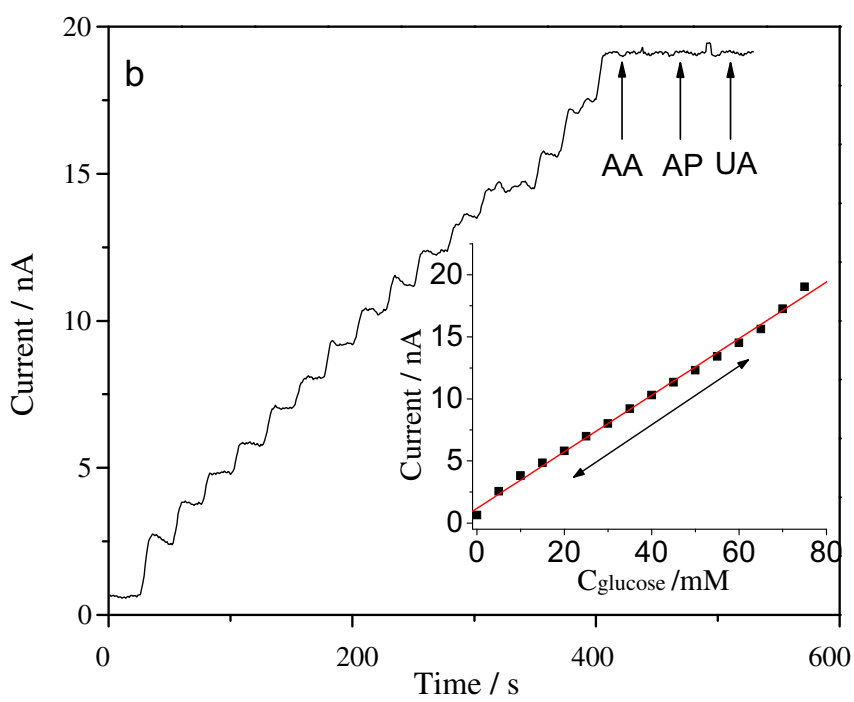

Fig. 6. Current-time response of the $\mathrm{Si}_{29}-\mathrm{Si}$ electrode to successive additions of equal amount of $5 \mathrm{mM}$ of glucose. The addition of $4 \mathrm{mM}$ of $\mathrm{AA}, 4 \mathrm{mM}$ of AP, and $4 \mathrm{mM}$ of $\mathrm{UA}$ to the solution does not cause changes in the electrode's response.

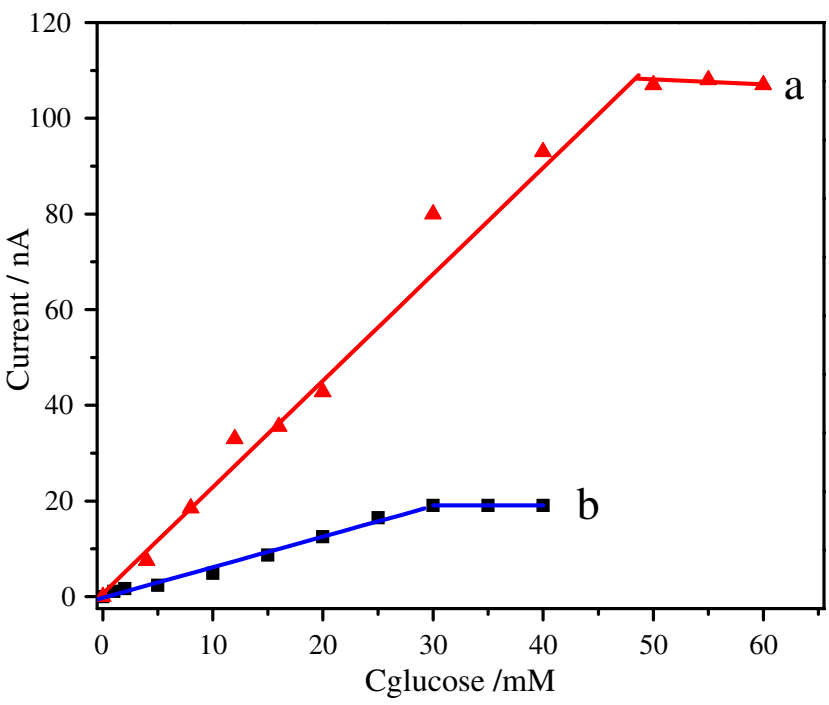

Fig. 7. Amperometric responses of an all silicon $\mathrm{Si}_{29}-\mathrm{Si}$ electrode, (a) and the GOx-Si electrode, (b) to glucose. The current values were measured at a potential of $0.7 \mathrm{~V}$ for both electrodes.

ticle film is more efficient than GOx active film in performing the oxidation of glucose and in transducting the detected electrical signal to the silicon electrode. This enhanced detection is likely to be the result of two effects. First, the particle is accessible to glucose, allowing oxidation to take place. In the case of GOx, glucose needs to enter a small opening on the enzyme in order to reach the FAD center. Moreover, when GOx is immobilized on an electrode, random molecular orientation may reduce the possibility for glucose to reach the FAD centers. Second, if the signal transduction process involves electron tunneling across the particle to the silicon electrode, the $1 \mathrm{~nm}$ tunnel distance is less than that for GOx, whose shortest tunnel distance is about $2 \mathrm{~nm}$ [13]. The schematic depicted in Fig. 8 suggests an additional advantage of using the $\mathrm{Si}_{29}$ particle in making miniature devices. The size of the

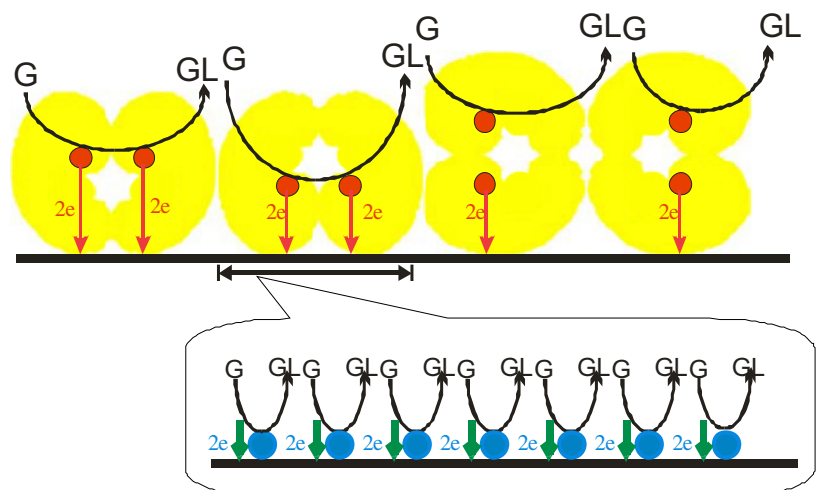

Fig. 8. Schematic comparison of silicon nanoparticles electrode and enzyme electrode to illustrate the advantages of using the Si nanoparticle compared to GOx in detecting glucose. Each "double-egg" shaped structure represents a GOx molecule, in which two FAD centers (smaller circles) reside. The Si nanoparticles are represented by green circles (larger circles). 
particle is $1 \mathrm{~nm}^{3}$, while the size of GOx is $6 \mathrm{~nm}$ $\times 5.2 \mathrm{~nm} \times 7.7 \mathrm{~nm}$. Thus, assuming each material forms a monolayer, the surface density of active sites is higher for the particle electrode than that for the GOx electrode. Within the two-dimensional extent of a GOx molecule, about $30 \mathrm{Si}_{29}$ particles can be accommodated.

We also studied the response while the sensor is exposed to external radiation. First we recorded the optical activity of the $1 \mathrm{~nm}$ colloid. When the colloid is excited by $355 \mathrm{~nm}$ pulsed radiation, blue luminescence can be observed with the naked eye, in room light, as shown in Fig. 9. The excitation, i.e., the absorption monitored at a specific emission wavelength (product of absorption and emission) was recorded on a photon counting spectro-fluorometer with a Xe arc lamp light source and $4 \mathrm{~nm}$ bandpass excitation and emission monochrometers. Fig. 10 gives the spectrum for excitation wavelength at $330,350,365$, and $400 \mathrm{~nm}$, showing a strong blue band that maximizes for $350 \mathrm{~nm}$. Fig. 11 proves some optical properties of the other sizes of particles available to us under illumination by light from a mercury lamp at $365 \mathrm{~nm}$ [11]. The bottom image in Fig. 11 (right to left) gives the emission of colloids of four members of the magic family 1.0, 1.67, 2.15 and $2.9 \mathrm{~nm}$ in diameter, after they have been separated, under excitation using a commercial low intensity UV source with an average wavelength of $365 \mathrm{~nm}$. The top view of the figure shows luminescence from blue, green and red colloidal crystals segregated according to magic sizes $1.0,1.67$ and $2.9 \mathrm{~nm}$ diameters. Fig. 12 gives the excitation spectra of the 1.0, $1.67,2.15$ and $2.9 \mathrm{~nm}$ diam particle monitored at emission wavelengths of $400,540,570$ and $600 \mathrm{~nm}$, respectively. They show local resonance structures at 3.44, 2.64, 2.39 and $2.11 \mathrm{eV}$ respectively. In addition to these properties, the particle exhibits interesting nonlinear optical properties

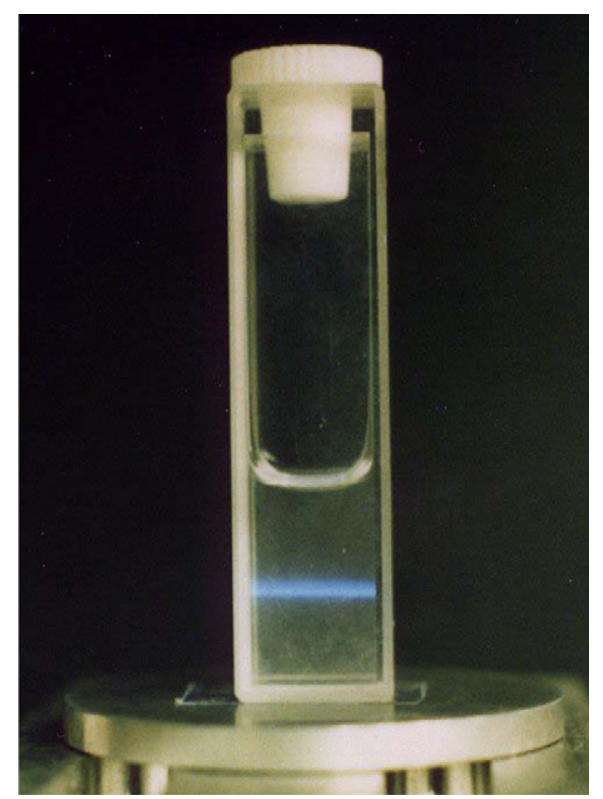

Fig. 9. A photo of a Si colloid excited by $355 \mathrm{~nm}$ radiation.

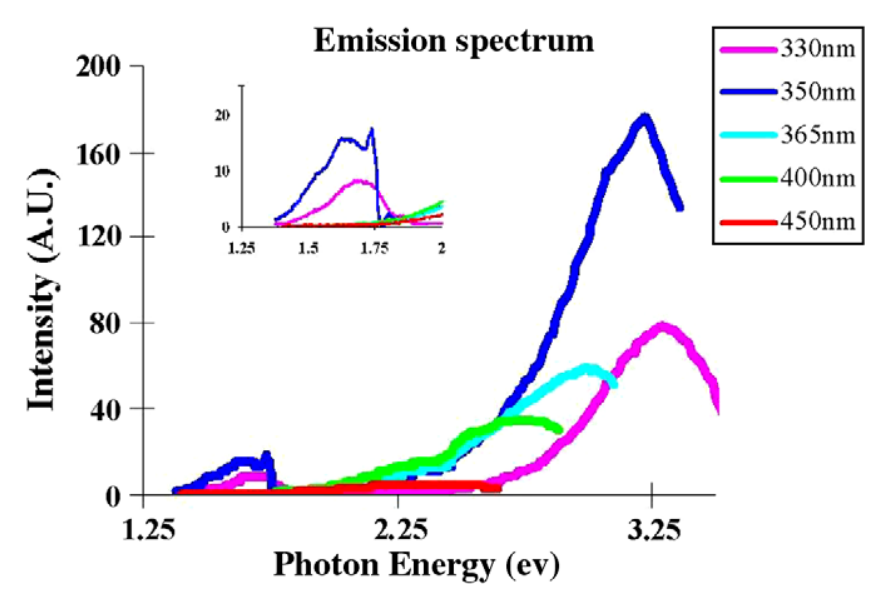

Fig. 10. Emission and excitation spectra (inset) of the particles.

such as laser oscillation [9] and second harmonic generation [10] in the visible part of the spectrum.

Since the constituent nanomaterial in our sensor are highly luminescent particles then the effect of light irradiation on the amperometric sensing of substance adds another dimension and functionality to our sensor that allows cross checking and extend its utility to more substances and possibly add to its selectivity and discrimation. Preliminary results show that the oxidation current depends on the intensity of the impringing light. UV light results in the creation of excitonic charge that may radiatively recombine to produce visible photolumines-
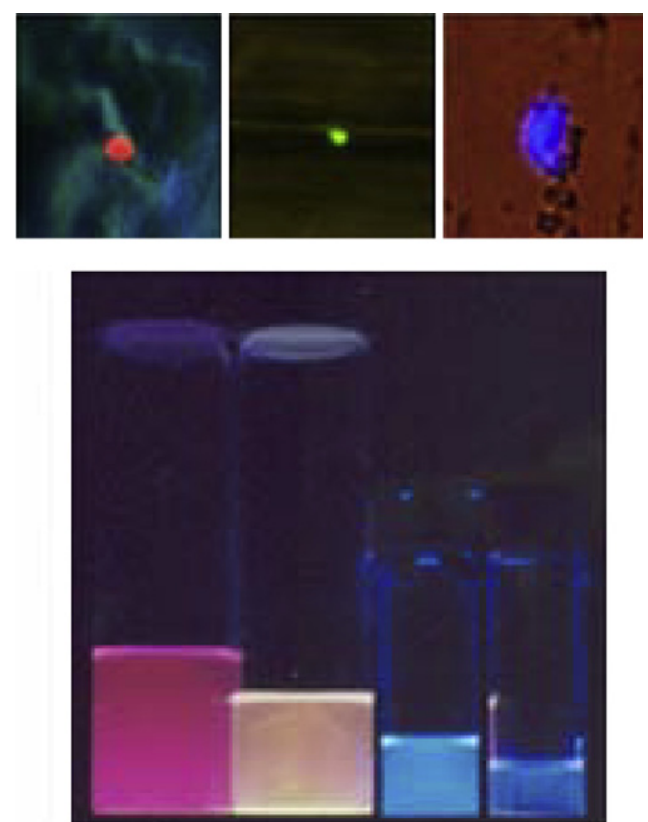

Fig. 11. (Bottom, right to left) Emission of colloids of four members of the magic family $1.0,1.67,2.15$ and $2.9 \mathrm{~nm}$ in diameter, after they have been separated, under excitation using a commercial low intensity UV source with an average wavelength of $365 \mathrm{~nm}$. (Color) (top view) Emission from blue, green and red colloidal crystals segregated according to magic sizes 1.0, 1.67 and $2.9 \mathrm{~nm}$ diameters. The crystals are illuminated by light from a mercury lamp. The background is due to a weak bright field. 


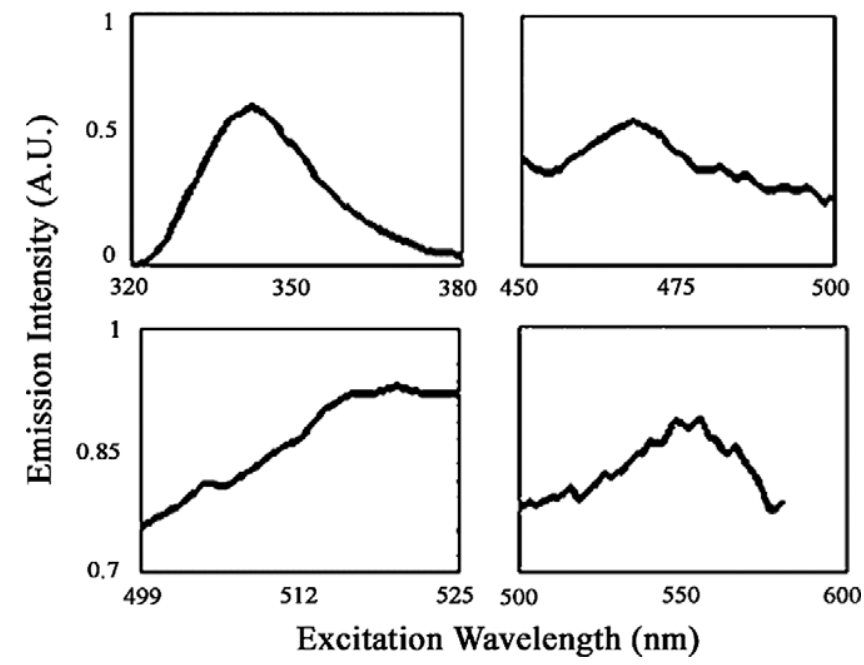

Fig. 12. Excitation spectra of the 1.0, 1.67, 2.15 and $2.9 \mathrm{~nm}$ diam particle monitored at emission wavelengths of $400,540,570$ and $600 \mathrm{~nm}$, respectively. They show local resonance structures at 3.44, 2.64, 2.39 and $2.11 \mathrm{eV}$ respectively.

cence, while white light produces excitonic charge that do not efficiently produce luminescence. We used light irradiation to modulate the charge in the sensor and hence modulate the amperometric response. Plans are underway to use this light effect in phase sensitive detection configuration to enhance the sensitivity. In fact, other nanoparticle configurations have shown to efficiently convert UV light into an electric signal, which enabled sensitive UV photoconductor devices $[19,20]$. Sensitive ultraviolet light detection may find applications as diverse as military and consumer and biological applications. Detection in the UV portion of the spectrum has applications in detection of biological agents in air. The photodetector configuration may be useful as a UV filter for monitoring enzyme reactions for example. High efficiency allows the study of extremely small samples, assays in small volumes, and sensor array for high-speed screening. Moreover, a thin film of particles coating the active region of a solar cell down converts UV to visible radiation, hencing shiding and perhaps increasing the efficiency.
In conclusion, we demonstrated that highly doped silicon substrate or conducting substrates that are decorated with fluorescent silicon nanoparticles can be used as amperometric sensors for glucose. We showed that the device is more sensitive than GOx electrode with improved selectivity, stability, and ameanability to miniturization and implantation for in vivo use. External light may be used to modulate the response, enabling phase sensitive detection.

\section{References}

[1] D.A. Gough, F.L. Anderson, J. Giner, C.K. Colton, J.S. Soeldner, Anal. Chem. 50 (1978) 941

[2] M.W. Hsiao, R.R. Adzic, E.B. Yeager, J. Electrochem. Soc. 143 (1996) 759.

[3] Y. Sun, H. Buck, T.E. Mallouk, Anal. Chem. 73 (2001) 1599.

[4] E. Shoji, M.S. Freund, J. Am. Chem. Soc. 123 (2001) 3383.

[5] J. Wang, M. Musameh, Y. Lin, J. Am. Chem. Soc. 125 (2003) 2408.

[6] G. Wang, K. Mantey, M.H. Nayfeh, S. Yau, Appl. Phys. Lett. 89 (2006) 243901.

[7] (a) O. Akcakir, J. Therrien, G. Belomoin, N. Barry, E. Gratton, M. Nayfeh, Appl. Phys. Lett. 76 (2000) 1857;

(b) G. Belomoin, J. Therrien, M. Nayfeh, Appl. Phys. Lett. 77 (2000) 779.

[8] (a) S. Rao, J. Sutin, R. Clegg, E. Gratton, M.H. Nayfeh, S. Habbal, A. Tsolakidis, R.M. Martin, Phys. Rev. B 69 (2004) 205319;

(b) L. Mitas, J. Therrien, G. Belomoin, M. Nayfeh, Appl. Phys. Lett. 78 (2001) 1918.

[9] M.H. Nayfeh, S. Rao, N. Barry, J. Therrien, G. Belomoin, A. Smith, S. Chaieb, Appl. Phys. Lett. 80 (2002) 121.

[10] M.H. Nayfeh, O. Akcakir, G. Belomoin, N. Barry, J. Therrien, E. Gratton, Appl. Phys. Lett. 77 (2000) 4086.

[11] G. Belomoin, J. Therrien, A. Smith, S. Rao, S. Chaieb, M.H. Nayfeh, Appl. Phys. Lett. 80 (2002) 841.

[12] G.B. Christison, H.A. MacKenzie, Med. Biol. Eng. Comput. 31 (1993) 284.

[13] G. Wang, S.-T. Yau, Appl. Phys. Lett. 87 (2005) 253901.

[14] Y. Xiao, F. Patolsky, E. Katz, J.F. Hainfeld, I. Willner, Science. 299 (2003) 1877.

[15] M. Zayats, E. Katz, I. Wilner, J. Am. Chem. Soc. 124 (2002) 2120.

[16] C. Bourdillon, C. Demaille, J. Gueris, J. Moiroux, J.M. Saveant, J. Am. Chem. Soc. 115 (1993) 12264.

[17] C. Bourdillon, C. Demaille, J. Moiroux, J.M. Saveant, J. Am. Chem. Soc. 115 (1993) 2.

[18] M.K. Weibel, H.J. Bright, J. Biol. Chem. 246 (1971) 2724.

[19] O. Nayfeh, S. Rao, A. Smith, J. Therrien, M. Nayfeh, IEEE Photon. Technol. Lett. 16 (2004) 1927.

[20] M. Nayfeh, S. Rao, O. Nayfeh, A. Smith, J. Therrien, IEEE Trans. Nanotechnol. 4 (2005) 660. 